Surgery for

Congenital Heart

Disease

\title{
Midterm results after restoration of the morphologically left ventricle to the systemic circulation in patients with congenitally corrected transposition of the great arteries
}

\author{
Stephen M. Langley, MD, FRCS (CTh), David S. Winlaw, FRACS, Oliver Stumper, MD, Rami Dhillon, MRCP, \\ Joseph V. de Giovanni, FRCP, John G. Wright, FRCP, Paul Miller, MRCP, Babulal Sethia, FRCS, \\ David J. Barron, MD, FRCS (CTh), and William J. Brawn, FRCS, FRACS
}

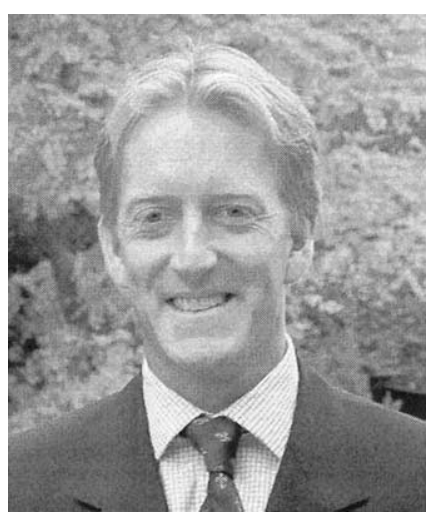

Dr Langley

From the Department of Cardiac Surgery, Diana Princess of Wales Children's Hospital, Birmingham, United Kingdom.

Read at the Eighty-second Annual Meeting of The American Association for Thoracic Surgery, Washington, DC, May 5-8, 2002.

Received for publication April 20, 2002; revisions requested June 13, 2002; revisions received Aug 3, 2002; accepted for publication Aug 15, 2002

Address for reprints: Stephen M. Langley, MD, FRCS (CTh), Department of Cardiac Surgery, Southampton General Hospital, Tremona Rd, Southampton SO16 64D, United Kingdom (E-mail: Stephen.Langley @ suht.swest.nhs.uk).

J Thorac Cardiovasc Surg 2003;125:1229-41

Copyright () 2003 by The American Association for Thoracic Surgery

$0022-5223 / 2003 \$ 30.00+0$

doi:10.1016/S0022-5223(02)73246-7
Objective: This study was undertaken to determine the outcomes of patients with congenitally corrected transposition of the great arteries after restoration of the morphologically left ventricle to the systemic circulation.

Methods: Between November 1991 and June 2001, a total of 54 patients (median age 3.2 years, range 7 weeks-40 years) with either congenitally corrected transposition of the great arteries $(n=51)$ or atrioventricular discordance with doubleoutlet right ventricle $(n=3)$ underwent anatomic repair. This comprised a Senning procedure in all cases plus arterial switch (double-switch group) in 29 cases (53.7\%), plus a Rastelli procedure (Rastelli-Senning group) in 22 cases (40.7\%), and plus intraventricular rerouting (Senning-tunnel group) in 3 cases (5.6\%). Left ventricular training by PA banding was performed before the double-switch operation in 9 of 29 cases (31\%). Follow-up is complete (median 4.4 years).

Results: Early mortality was $5.6 \%(\mathrm{n}=3)$, with 2 late deaths. Kaplan-Meier survivals ( \pm SEM) were $94.4 \% \pm 3.1 \%$ at 1 year and $89.7 \% \pm 4.4 \%$ at 9 years. Survivals at 7 years were $84.9 \% \pm 7.1 \%$ in the double-switch group and $95.5 \% \pm 4.4 \%$ in the Rastelli-Senning group $(P=.32)$. Of the 49 survivors, $46(94 \%)$ were in New York Heart Association functional class I. Six have acquired new left ventricular dilatation or impaired systolic ventricular function. Four patients in the double-switch group had moderate aortic valve regurgitation develop, and 2 of them required valve replacement. Overall freedoms from reoperation at 1 and 9 years were $94.2 \% \pm 3.3 \%$ and $77.5 \% \pm$ $9.0 \%$, with no significant difference between the groups $(P=.60)$.

Conclusions: Anatomic repair of congenitally corrected transposition of the great arteries can be carried out with low early mortality. Excellent functional status can be achieved, with good midterm survival. Continued surveillance is necessary for patents with valved conduits and to determine the longer-term function of the aortic valve and the morphologically left ventricle in the systemic circulation.

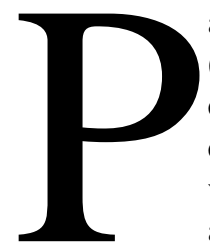
atients with congenitally corrected transposition of the great arteries (CCTGA) are usually seen as a result of the additional lesions that are commonly associated with this condition. The more important associations are tricuspid valve regurgitation (the systemic atrioventricular valve), ventricular septal defect (VSD), pulmonary stenosis or atresia, and complete heart block. Depending on the specific anatomy in each patient, a conventional or classic surgical repair of CCTGA may involve tricuspid 
valve repair or replacement, VSD closure, or a left ventricle (LV)-pulmonary artery (PA) conduit, with the morphologically right ventricle $(\mathrm{RV})$ remaining the systemic ventricle. Although classic repair may result in excellent short-term results, the long-term function of the RV in the systemic circulation remains a concern. Previous series have documented a high incidence of heart failure related to systemic RV dysfunction and a high mortality associated with this problem. ${ }^{1,2}$ Systemic ventricular failure may affect as many as $40 \%$ of patients within 3 years of a classic repair. ${ }^{3}$ Similarly, systemic RV failure is a well-recognized problem in patients after atrial switch for atrioventricular concordance and transposition of the great arteries. ${ }^{4}$ The situation in CCTGA tends to be worse, however, because of its frequent association with morphologic abnormalities of the tricuspid valve and the resultant incompetence.

Because of the disappointing results with the classic approach, more recently surgical repair has been directed toward anatomic repair in which the morphologically LV is restored to the systemic circulation. Anatomic repair of CCTGA was first undertaken in 1989, and sporadic reports of individual cases began to emerge in the early $1990 \mathrm{~s} .{ }^{5-7} \mathrm{~A}$ number of other centers have since reported their early results. ${ }^{8-13}$ In those patients with CCTGA without pulmonary stenosis or atresia, anatomic repair comprises an atrial switch and an arterial switch (double-switch procedure), with closure of any VSD present. Patients with subpulmonary ventricular outflow tract obstruction undergo an atrial switch, VSD closure, and placement of an RV-PA conduit.

Following on from the report of our early experience of anatomic correction for CCTGA, ${ }^{14}$ the aim of this study was to determine the outcomes of all patients with CCTGA undergoing anatomic repair at the Diana Princess of Wales Children's Hospital (Birmingham, UK) during the past 10 years. Outcomes were examined with regard to early mortality and morbidity, midterm survival, freedom from reoperation, and current functional status.

\section{Methods}

Between November 1991 and June 2001, a total of 54 patients with atrioventricular discordance underwent anatomic correction at the Diana Princess of Wales Children's Hospital. Fifty-one of these patients also had ventriculoarterial discordance and thus CCTGA. The remaining 3 patients had double-outlet RV (DORV) in addition to atrioventricular discordance. The median age of the patients was 3.1 years (range 7 weeks-40 years, interquartile range [IQR] 1.8-5.8 years), and their median weight was $13.4 \mathrm{~kg}$ (range $3.4-$ $61.4 \mathrm{~kg}$, IQR $10.2-17.5 \mathrm{~kg}$ ). Thirty-nine patients (72\%) were male.

The individual surgical strategy was determined by the associated abnormalities, particularly the presence or absence of pulmonary stenosis or atresia. Twenty-nine patients without pulmonary stenosis underwent an atrial switch (Senning procedure) and an arterial switch (double-switch group). The remaining 22 patients with CCTGA underwent an atrial switch together with closure of the VSD and valved conduit placement from the RV to the PAs
(Rastelli-Senning group). The 3 patients with atrioventricular discordance and DORV underwent an atrial switch with creation of an intraventricular tunnel to route the pulmonary venous blood through the mitral valve and LV to the aorta (Senning-tunnel group).

\section{Double-Switch Group}

Of the 29 patients who underwent double-switch procedures, 26 $(89.7 \%)$ had situs solitus with levocardia (cardiac apex to the left), 2 had normal situs with mesocardia (apex in the midline), and 1 had situs inversus with dextrocardia (apex to the right). The atrial septum was intact in 24 patients, 4 patients had a patent foramen ovale, and 1 had previously undergone atrial septectomy. Before the operation, 11 patients had an intact ventricular septum with three of these having undergone previous VSD closure. The remaining 18 underwent VSD closure at the time of the doubleswitch procedure. The coronary anatomy was remarkably consistent, with the left anterior descending and circumflex coronary arteries arising from a single ostium in the anterior facing sinus and the right coronary artery arising from the posterior facing sinus. In 1 case the left anterior descending and circumflex coronary arteries arose from two separate ostia in the anterior facing sinus.

Fifteen patients had morphologic abnormalities of the tricuspid valve, including 3 with Ebstein-like malformation alone, 5 with thickened dysplastic leaflets, 6 with both Ebstein-like malformation and dysplastic leaflets, and 1 with a double orifice and straddling valve. Moderate or severe tricuspid regurgitation was present in 18 of the 29 patients $(62.1 \%), 11$ of whom had either Ebsteinlike malformation (some degree of apical displacement of the septal leaflet), dysplastic thickened leaflets, or both. The other 7 patients with tricuspid regurgitation had normal tricuspid valve morphologic features (Figure 1). Only 7 patients undergoing double-switch procedures had both a structurally normal valve and no tricuspid regurgitation. One patient had a dysplastic but competent mitral valve, and 1 had mitral regurgitation in association with a poorly functioning and dilated LV. The aortic valve was bicuspid in 1 patient and tricuspid in the others. The pulmonary (neoaortic) valve was bicuspid in 3 patients, quadricuspid in 1 patient, and tricuspid in 25 patients, 1 of whom had free incompetence in association with pulmonary hypertension. Three patients had some degree of subpulmonary stenosis caused by fibrous or fibromuscular tissue, but no patients had pulmonary stenosis at the valvular level. Other cardiac abnormalities included aneurysmal PAs ( $\mathrm{n}=$ $2)$, subaortic stenosis $(n=1)$, a left superior vena cava $(n=1)$, and previous aortic coarctation $(\mathrm{n}=3)$.

Of the 29 patients undergoing double-switch operations, $23 \mathrm{had}$ undergone a total of 28 previous procedures (Table 1 ). Twenty-one had undergone previous PA banding. In 13 of these cases the band had been placed early in the first year of life to reduce pulmonary blood flow in the presence of a VSD. One of these patients, early in our series in 1993, underwent PA debanding with VSD closure, leaving the RV in the systemic circulation. Within 5 months severe tricuspid regurgitation and RV failure had developed. The pressure in the LV was too low to proceed directly to a double-switch procedure. A PA band was therefore placed again, this time to train the LV to become the systemic ventricle. A further 8 patients underwent PA banding to train the LV. 


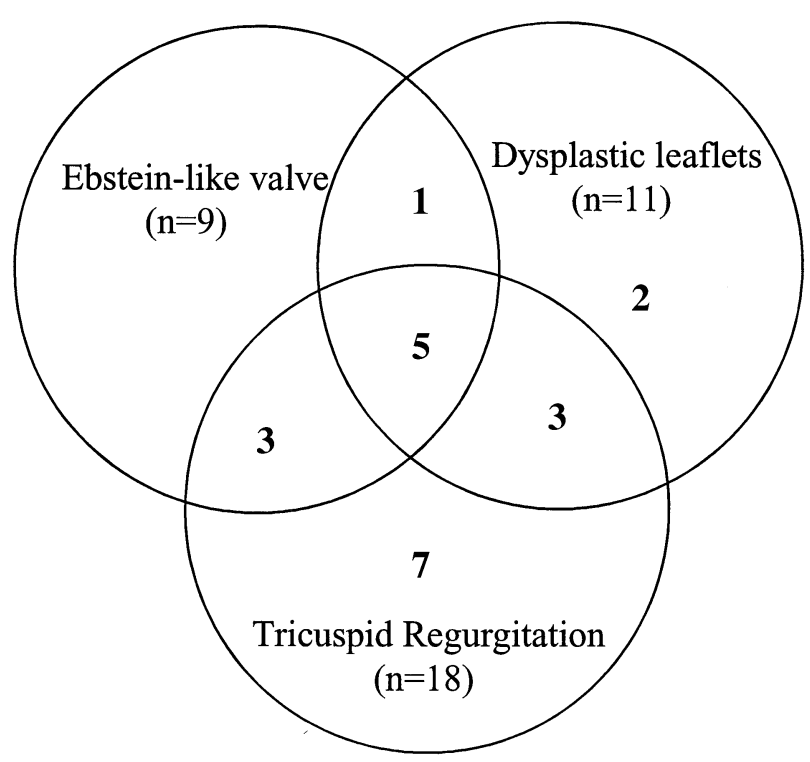

Figure 1. Tricuspid valve morphologic characteristics and tricuspid incompetence in patients undergoing double-switch procedures. Venn diagram depicting 21 of 29 patients in double-switch group with either tricuspid valve morphologic abnormalities, tricuspid regurgitation, or both. One further patient had doubleorifice straddling valve. Seven remaining patients had both normal tricuspid valve morphologic characteristics and competent tricuspid valve.

PA banding was undertaken through a median sternotomy. Before transfer of the patient to the operating room, an LV pressure monitoring line was placed through the innominate vein under echocardiographic or angiographic control. The PA was dissected out, the circumference of the PA was measured, and a PA band was then placed to reduce the circumference of the PA by half. The band was then tightened or loosened to adjust the pressures in the banded ventricle to about $80 \%$ of systemic pressure when possible. During the procedure, LV function was monitored by either transesophageal or epicardial echocardiography, and the band was adjusted so that the ventricular function was maintained with only mild systolic dilatation of the LV. The median time from initial banding to definitive surgery was 13 months (IQR 4-14 months). Two patients required tightening of the band at 6 and 16 months after the original banding. At cardiac catheterization before the double-switch procedure, the LV pressure equaled the systemic level in 4 patients and was suprasystemic in 1 . In the remaining 4 patients, the LV/RV pressure ratio was greater than $70 \%$.

\section{Rastelli-Senning Group}

Of the 22 patients undergoing Rastelli-Senning repair, 16 (73\%) had situs solitus: 4 with levocardia, 1 with mesocardia, and 11 with dextrocardia (50\%). Five patients had situs inversus: 4 with levocardia and 1 with mesocardia. One patient had right atrial isomerism with dextrocardia. The atrial septum was intact in 13 patients, 7 had a patent foramen ovale, and 1 had a secundum atrial septal defect. One child had undergone previous balloon atrial septostomy. All 22 patients had a VSD with either pulmonary
TABLE 1. Previous procedures in 23 of the 29 patients undergoing double-switch procedures

Procedure No.

PA band for VSD 10

PA band for VSD and coarctation repair

PA debanding and VSD closure

Arterial switch, PA banding for VSD and atrial septectomy

PA band to train morphologically LV

PA band to train morphologically LV and tricuspid annuloplasty

PA band tightened

Coarctation repair

VSD closure, tricuspid annuloplasty, and permanent pacemaker

Tricuspid valve replacement and VSD closure

Total procedures

atresia $(n=15)$ or pulmonary stenosis $(n=7)$. The coronary anatomy was as described for the double-switch group, except for 1 case in which the left anterior descending coronary artery arose anomalously from the right coronary artery. Morphologic abnormalities of the tricuspid valve were unusual, with just 1 patient with an Ebstein-like malformation and resultant significant tricuspid regurgitation. In addition, 2 patients had mild regurgitation in the presence of a normal-looking tricuspid valve. Other cardiac abnormalities included major aortopulmonary collateral arteries in 2 patients and absent intrapericardial PAs in 1. Two patients had a left superior vena cava, and in 1 patient there was azygous continuation of the inferior vena cava. A total of 29 systemic-PA shunts had previously been undertaken in 19 of the 22 patients undergoing Rastelli-Senning repairs. Ten patients had undergone two previous shunts, usually as separate procedures but in 2 cases on the same occasion. In addition, 1 patient had undergone unifocalization of major aortopulmonary collateral arteries, initially on the right side and subsequently on the left side as well. Previous interventions also included embolization of major aortopulmonary collateral arteries in 1 patient, an atrial septostomy in 1 patient, and balloon dilatation of PAs in 3 patients.

\section{Senning-Tunnel Group}

Of the 3 patients, 2 had situs solitus with levocardia and 1 had situs inversus with levocardia. All 3 patients had an intact atrial septum and a VSD. No patients had tricuspid regurgitation; however, 1 had a rather dysplastic valve with thickened leaflets. No patients had pulmonary stenosis. Two patients had muscular subaortic stenosis, and 1 had a previous aortic coarctation. All 3 patients had previously undergone neonatal PA banding to reduce pulmonary blood flow. In addition, 1 patient had undergone neonatal aortic coarctation repair and another had undergone an exploratory operation 3 years previously. At that time it was considered that the patient had double-inlet LV with a small RV, and septation was therefore not undertaken.

\section{Indications for Surgery}

The indication for a double-switch procedure varied with individual patient anatomy. The patients fell into three main categories. 
TABLE 2. Concomitant procedures in 25 of the 29 patients undergoing double-switch procedures

\begin{tabular}{lr}
\hline Procedure & No. \\
\hline VSD closure (total) & 18 \\
Tricuspid valve annuloplasty & 2 \\
Tricuspid valve replacement & 1 \\
Resection straddling tricuspid valve tissue & 1 \\
Removal of triscuspid annuloplasty ring & 1 \\
Mitral valve annuloplasty & 1 \\
Aortic root replacement & 1 \\
Resection of RV outflow tract muscle & 1 \\
Resection of subpulmonary membrane & 1 \\
Placement of permanent pacing wires & 2 \\
Pulmonary artery reconstruction & 3 \\
Total procedures & 32
\end{tabular}

The first group included those patients with a VSD who had previously undergone PA banding to reduce pulmonary blood flow and who were now beginning to outgrow the band. The second category of patients included those with congestive cardiac failure as a result of systemic (right) ventricular failure and tricuspid regurgitation. Five patients in this category in this series were dependent on both ventilatory and inotropic support. The third group of patients included those who had undergone PA banding to train the $\mathrm{LV}$ in the presence of increasing severe tricuspid regurgitation. Surgery was indicated in this group after an adequate response of the LV to banding. Among the 6 patients who had long-term band placement ( $\geq 6$ months), severe tricuspid regurgitation was still present in 3 at the time of the anatomic correction. Among the other 3 patients, the tricuspid regurgitation had reduced from severe to moderate in 2 and from severe to mild in 1 .

The indications for a Rastelli-Senning procedure were increasing cyanosis and limitation in physical activity, usually after previous systemic-PA shunting early in life in a child with CCTGA, pulmonary stenosis or atresia, and a VSD. In the Senning-tunnel group, the indication for surgery was the same as for those in the double-switch group who had undergone previous PA banding to reduce pulmonary blood flow; that is, to undertake septation before the child began to outgrow the band.

\section{Operative Details}

All patients were cooled on cardiopulmonary bypass to a core temperature of $18^{\circ} \mathrm{C}$. The median cardiopulmonary bypass time for the whole series was 149 minutes (IQR 120-176 minutes). Intermittent cold crystalloid cardioplegia was used for myocardial protection. The median aortic crossclamp time was 131 minutes (IQR 115-143 minutes). The pump flow rate was reduced and the circulation was arrested for a number of separate short periods during each procedure. This was particularly necessary during the Senning procedure when the venous chambers were behind the ventricles. The median total circulatory arrest time was 43 minutes (IQR 32-57 minutes). On-table transesophageal or epicardial echocardiography was used routinely to assess the systemic and pulmonary venous pathways, the neoaortic valve, and ventricular function.

All 29 patients in the double-switch group underwent a Senning procedure, and 28 of these also underwent an arterial switch during the same operation. One patient had previously undergone an arterial switch together with PA banding and atrial septectomy 4 months previously. This patient had pulmonary hypertension at systemic levels with a VSD, an aneurysmal PA, and tracheobronchomalacia. Before proceeding to a Senning procedure, the PA pressure reduced to normal, allowing septation of the heart. In 17 of the 29 patients the Lecompte maneuver with relocation of the PAs anterior to the aorta was used. The coronary arteries were all relocated to the facing sinuses of the neoaorta with the use of the medially hinged flap technique. A VSD was present in 18 patients. This was closed through the mitral valve in 13 patients, through the tricuspid valve in 2 , and through the great vessels in 3 . Concomitant procedures undertaken at the same time as the double-switch are detailed in Table 2 .

In the Rastelli-Senning group, all 22 patients underwent a Senning procedure together with closure of the VSD, committing the LV to the aorta and placement of a conduit from the RV to the PA. Any previous systemic-PA shunts were ligated. The VSD was closed through the RV alone in 21 patients and through both the $\mathrm{RV}$ and the mitral valve in 1 patient. The sutures were placed on the RV side of the septum in an attempt to avoid the conduction system. In 4 patients the VSD was enlarged before patch closure to prevent LV outflow tract obstruction. In 1 patient with tricuspid valve tissue attached to the inferior part of the VSD, the septal tricuspid leaflet was detached and then resited to ventricular margin after closure of the VSD. A Hancock ${ }^{7}$ valved conduit (Medtronic, Inc, Minneapolis, Minn) was used to connect the RV to the PAs in 21 patients, and an aortic homograft $(19 \mathrm{~mm})$ was used in 1 patient. Hancock conduit size varied between $14 \mathrm{~mm}$ and $22 \mathrm{~mm}$, with most patients having the smaller sizes. In 5 patients (27\%) a 14-mm conduit was used, and in 9 patients $(41 \%)$ a $16-\mathrm{mm}$ conduit was used. In a further 5 patients an 18 -mm conduit was used, and 20-mm and 22-mm conduits were used in 1 patient each. The conduit was placed on the left side of the aorta in 15 (68\%) patients and on the right in 7 patients. The position of the conduit in relation to the aorta was largely determined by the amount of cardiac dextrorotation and the accessibility of the main branch PAs. Three patients underwent main branch PA augmentation with a pericardial patch, and the patient with absent intrapericardial PAs underwent implantation of a 10-mm polytetrafluoroethylene ${ }^{7}$ tube to connect the right and left sides. Additional procedures included infundibular muscle resection beneath the aortic valve in one patient, aortic valve resuspension in another and ligation of a left superior vena cava in another patient. Although attempts were made to place the conduit away from the sternum this was not usually possible so the sternum was always closed with a polytetrafluoroethylene ${ }^{7}$ pericardial membrane placed between the conduit and the back of the sternum.

In the Senning-tunnel group, all 3 patients underwent a Senning procedure together with closure of the VSD with creation of an intraventricular tunnel to route the pulmonary venous blood through the mitral valve and LV to the aorta. A right ventriculotomy was used in all 3 cases to allow inspection of the internal anatomy and to septate the VSD to the aorta in 2 patients. In the third patient the VSD was closed through the mitral valve. Two patients required resection of subaortic infundibular muscular stenosis. In all 3 patients the PA was debanded and enlarged with a bovine pericardial patch. 
After surgical correction, the patients were transferred to the intensive care unit. In 34 of the 54 patients the sternum was not formally closed in the operating room. In 26 of these patients only the skin was closed, and in 8 patients a polytetrafluoroethylene ${ }^{7}$ membrane* was sewn to the skin edges. The median time to formal chest closure was 1 day (range 1-6 days, IQR 1-2 days). Median intensive care unit stay was 4 days (IQR 3-6 days), and the median hospital stay was 14 days (IQR 11-26 days).

\section{Follow-Up}

All patients have been followed up at least every 6 months since discharge from hospital by a pediatric cardiologist either in our own unit or in the patient's referring hospital elsewhere in the United Kingdom or overseas. Current clinical status was graded according to the New York Heart Association (NYHA) classification, with ventricular and valvular function primarily determined by echocardiography. Ventricular function was classified semiquantitatively as good, moderate, or poor. Cardiac catheterization was undertaken electively in local patients at about 5 years after the correction or when more precise hemodynamic or angiographic information was required because patients either had symptoms or echocardiographic results that raised some concern. Follow-up was complete, with a median time of 4.4 years and a total follow-up of 223 patient-years.

\section{Statistical Analysis}

All continuous variables are expressed as median with IQR. A commercial statistical software package (SPSS for Windows version 10; SPSS Inc, Chicago, Ill) was used for data analysis. Survival and freedom from reoperation probability estimates were determined by the Kaplan-Meier product limit method and compared with the log-rank test; variability is expressed as \pm SEM.

\section{Results}

\section{Early Mortality}

In-hospital or 30 day mortality was $5.6 \%$ (3 patients). There was 1 death in the operating room, 1 at 3 postoperative days, and 1 at 49 days. The cause of death for the first 2 patients was myocardial failure, and the cause for the third patient was myocardial infarction. The patient who died in the operating room was a 2-year-old girl who before the operation had had severe congestive cardiac failure, together with pulmonary hypertension and free tricuspid regurgitation in a previously placed prosthetic tricuspid valve. She underwent a double-switch procedure with mechanical tricuspid valve replacement. It was not possible to wean the heart from bypass at the end of the procedure. The second patient to die was a 23-year-old man with CCTGA, a large VSD, high-flow pulmonary vascular disease with pulmonary incompetence, and an aneurysmal PA. He underwent a double-switch procedure and aortic root replacement with a mechanical valve. A low cardiac output state developed after the operation, necessitating hemofiltration for renal failure, and he died on day 3 of myocardial failure. The third

*Gore-Tex membrane, registered trademark of W. L. Gore \& Associates (UK) Ltd., Livingston, Scotland. patient was a 2-year-old girl who had undergone a RastelliSenning procedure but had continued to have a low cardiac output together high left atrial pressures after the operation. Cardiac catheterization demonstrated a gradient of just 15 mm Hg across the LV outflow tract; however, the LV was rather small. The repair was taken down, but the patient remained in the intensive care unit with myocardial failure and dialysis-dependent renal failure and died 4 weeks later. At autopsy, the RV showed evidence of both old and recent infarction in association with ischemic fibrosis.

\section{Early Morbidity}

The most frequent significant early morbidity was complete heart block with the subsequent need for implantation of a permanent pacemaker. Before the operation, 3 patients were in complete heart block or variable complete heart block. In addition, 8 patients acquired new atrioventricular block after the operation. Eleven patients underwent implantation of a permanent pacemaker, and 1 subsequently reverted to sinus rhythm. In total, therefore, 7 patients $(13.7 \%)$ acquired new permanent complete heart block. Of these, 4 had undergone a double-switch procedure, 2 a Rastelli-Senning procedure, and 1 a Senning-tunnel procedure. Other morbidity included chest reopening in the first 24 hours in 5 patients. The indication for this was excessive blood loss in the drains in 2 cases and to exclude tamponade in the other 3. Twelve patients required drainage of a postoperative pleural effusion. Ten of these patients had undergone a Rastelli-Senning repair, and in 8 of the 10 the effusion was right sided. Three patients acquired significant renal dysfunction necessitating hemofiltration, and 2 of them subsequently died early. Two patients had pulmonary hypertensive crises that resolved with nitric oxide, epoprostenol, and phenoxybenzamine. One patient had bilateral cerebral infarction as a result of a hypoxic ischemic injury, which resulted in spastic quadriplegia.

\section{Late Mortality}

At follow-up to date there have been 2 late deaths. One of the patients who died was a 3-year-old girl with poor preoperative LV function who had undergone a doubleswitch procedure and who died 1 year after her surgery. She was a patient from overseas who died as a result of viral myocarditis on a background of poor LV function. The second late death was at 3 years after a double-switch procedure and subpulmonary membrane resection in a 7-year-old boy. He acquired aortic regurgitation and LV dysfunction and underwent prosthetic aortic valve replacement and mitral valve repair of a dysplastic mitral valve 5 months after his initial operation. His LV function continued to deteriorate, however, and he died after a cardiac arrest while on the active transplant list. Including early mortality, the Kaplan-Meier survival for the whole series 


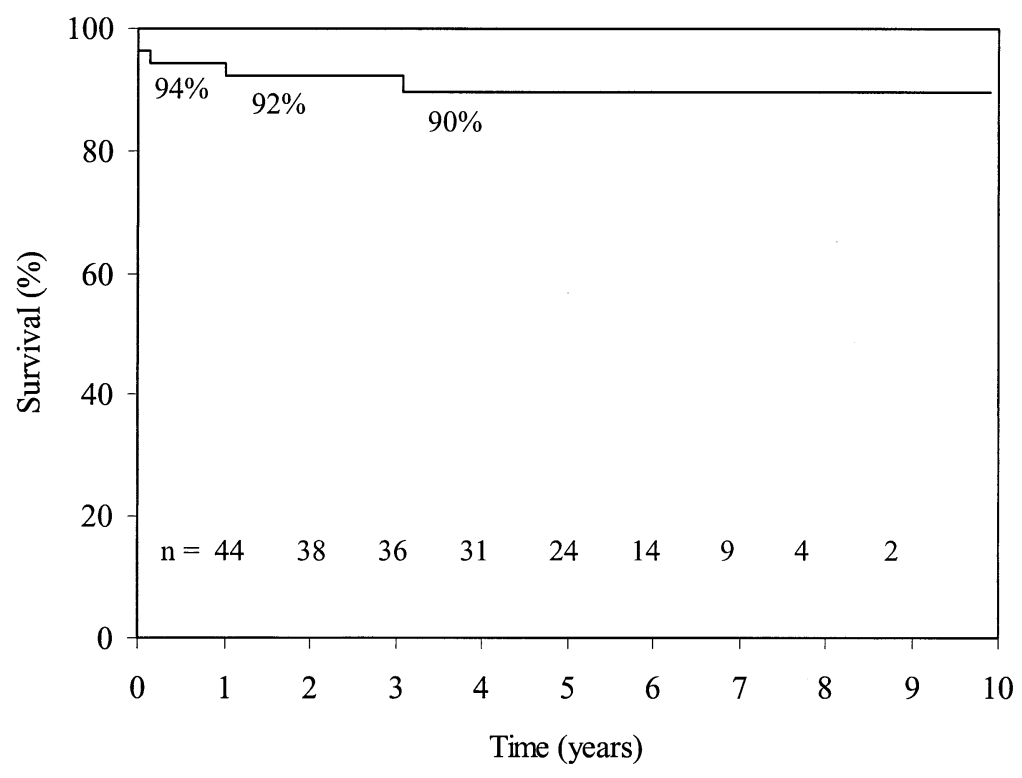

Figure 2. Kaplan-Meier survival curve for entire series. Kaplan-Meier survival for whole series was $94.4 \% \pm 3.1 \%$ at 1 year, falling to $89.7 \% \pm 4.4 \%$ by 4 years, and from there on out to 9 years.

was $94.4 \% \pm 3.1 \%$ at 1 year, falling to $89.7 \% \pm 4.4 \%$ at 4 years and from there on out to 9 years (Figure 2). When the double-switch and Rastelli-Senning groups were analyzed separately, survivals were $93.1 \% \pm 4.7 \%$ at 1 year and $84.9 \% \pm 7.1 \%$ at 5 and 7 years in the double-switch group, compared with $95.5 \% \pm 4.4 \%$ at 1,5 , and 7 years in the Rastelli-Senning group (Figure 3). The difference in the survival curves between the two groups was not statistically significant $(P=.32)$.

\section{Reinterventions}

Seven patients have undergone reoperation, and in addition there have been 6 interventional catheter procedures. In the double-switch group 2 patients have undergone aortic valve replacement for aortic regurgitation, with 1 of these also undergoing mitral valve repair, and a further patient has undergone cardiac transplantation at another institution for LV failure. This patient had previously undergone PA banding for LV training but had a suprasystemic LV pressure with an LV that was failing at the time of the double-switch procedure. In the Rastelli-Senning group, 3 patients have undergone a conduit change and 1 patient has undergone takedown of the repair as discussed previously. The freedoms from reoperation for the entire series were 94.2\% \pm $3.3 \%$ at 1 year, $85.3 \% \pm 5.7 \%$ at 5 years, and $77.5 \% \pm$ $9.0 \%$ at 9 years (Figure 4). When the double-switch and Rastelli-Senning groups were analyzed separately, freedoms from reoperation were $92.6 \% \pm 5.0 \%$ at 1 year and $87.2 \% \pm 7.1 \%$ at 5 and 7 years in the double-switch group and $95.5 \% \pm 4.4 \%$ at 1 year, $81.8 \% \pm 9.7 \%$ at 5 years, and $68.2 \% \pm 14.8 \%$ at 7 years in the Rastelli-Senning group
(Figure 5). The difference in the reoperation curves between the two groups was not statistically significant $(P=.60)$. The 6 interventional catheter procedures include 1 in the double-switch group who has undergone stenting of the superior vena cava for baffle obstruction and 3 in the Rastelli-Senning group who have undergone balloon dilatation of the superior vena cava. Two additional interventions in the Rastelli-Senning group include balloon dilatation of a PA in 1 patient and device closure of a residual VSD in another.

\section{Functional Status}

Of the 49 survivors, 46 (94\%) are in NYHA functional class I at most recent follow-up, including the patient who underwent cardiac transplantation for LV failure. Of the 3 remaining patients, 2 are in NYHA functional class II and 1 is in NYHA functional class III. Both patients in NYHA class II have moderately impaired LV function, 1 in the presence of aortic regurgitation. The patient in NYHA class III has poor LV function and has undergone cardiac transplantation assessment but currently remains too well for a transplant. Three further patients have echocardiographic evidence of impaired LV function, but all remain in NYHA class I (Table 3).

Four patients in the double-switch group have acquired postoperative aortic regurgitation. Three of these had undergone previous PA banding. As discussed previously, 2 patients in the double-switch group, 1 of whom subsequently died of myocardial failure, have undergone aortic valve replacement. The other patient is alive in NYHA class I and has good LV function. A third patient has moderate 


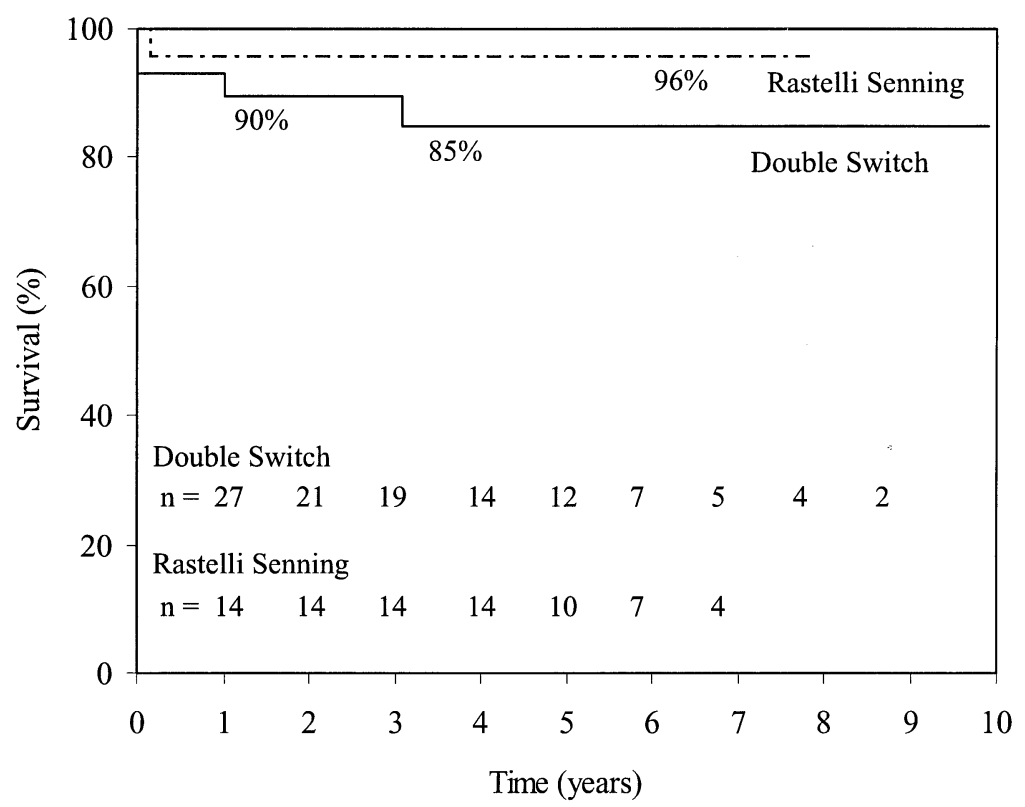

Figure 3. Kaplan-Meier survival curves for double-switch and Rastelli-Senning groups analyzed separately. Survivals for double-switch group were $93.1 \% \pm 4.7 \%$ at 1 year and $84.9 \% \pm 7.1 \%$ at 7 years; survival for Rastelli-Senning group was $95.5 \% \pm 4.4 \%$ at 1 and 7 years. Difference between groups in survival curves was not statistically significant $(P=.32)$.

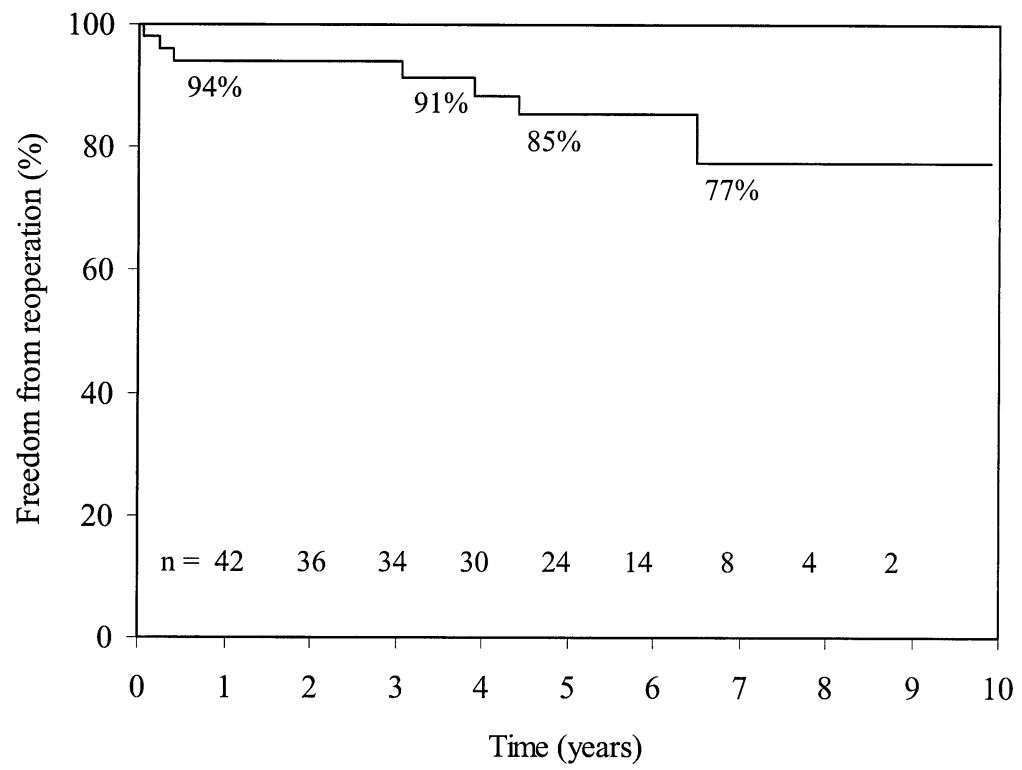

Figure 4. Freedoms from reoperation for entire series: $94.2 \% \pm 3.3 \%$ at 1 year, $85.3 \% \pm 5.7 \%$ at 5 years, and $77.5 \%$ $\pm 9.0 \%$ at 9 years.

aortic regurgitation, with resulting impaired LV function. In addition, 1 patient in the double-switch group has moderate aortic regurgitation with normal LV systolic function. Of the 18 patients in the double-switch group with moderate or severe tricuspid regurgitation before the operation, 2 died early, 2 died late, and 1 has undergone cardiac transplantation. Of the remaining 13 patients, 2 have moderate regurgitation. Both these patients had severe regurgitation and an Ebstein-like valve before the operation. The remaining patients have trivial or no tricuspid regurgitation. The patient 


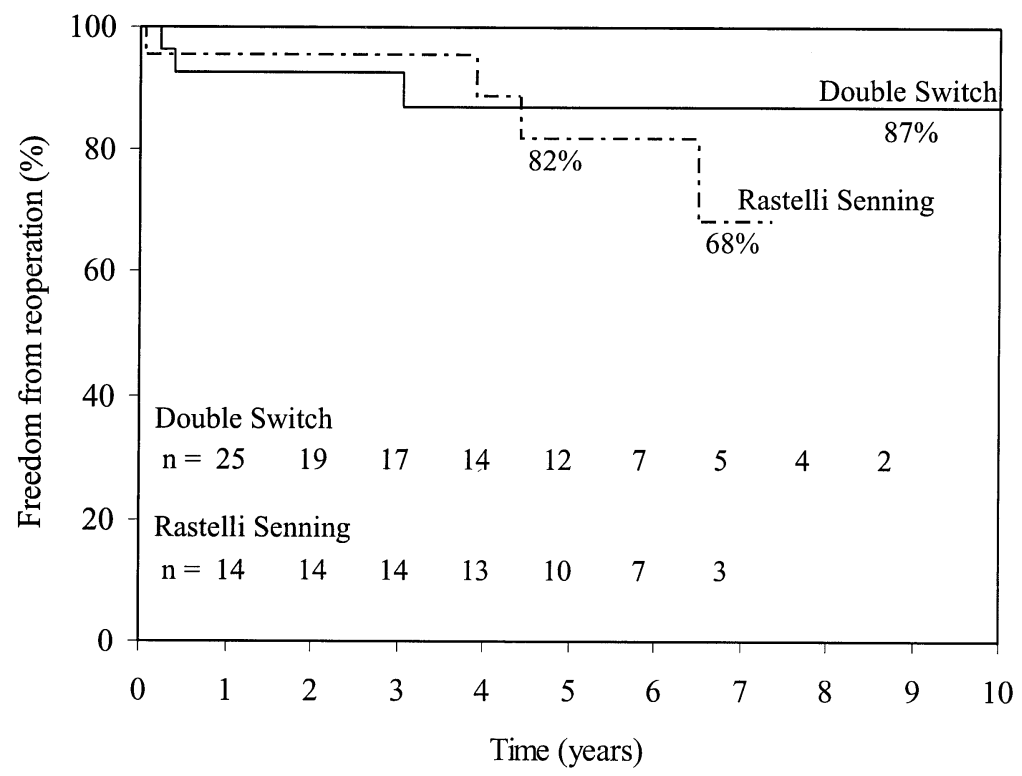

Figure 5. Freedoms from reoperation for double-switch and Rastelli-Senning groups analyzed separately. Freedoms from reoperation for double-switch group were $\mathbf{9 2 . 6} \% \pm \mathbf{5 . 0} \%$ at 1 year and $\mathbf{8 7 . 2} \% \pm \mathbf{7 . 1} \%$ at $\mathbf{5}$ and 7 years; freedoms for Rastelli-Senning group were $95.5 \% \pm 4.4 \%$ at one year, $81.8 \% \pm 9.7 \%$ at 5 years, and $68.2 \% \pm 14.8 \%$ at 7 years. Difference between groups in freedom from reoperation curves was not statistically significant $(\boldsymbol{P}=$ .60).

TABLE 3. Details of the 9 patients with postoperative impairment of LV function

\begin{tabular}{ccccccccc}
\hline Case & Age & Sex & Operation & $\begin{array}{c}\text { Previous } \\
\text { PA }\end{array}$ & $\begin{array}{c}\text { Preoperative } \\
\text { LV function }\end{array}$ & $\begin{array}{c}\text { Postoperative } \\
\text { LV function }\end{array}$ & $\begin{array}{c}\text { Postoperative } \\
\text { aortic } \\
\text { regurgitation }\end{array}$ & Current status \\
\hline 1 & $3 y$ & F & DS & No & Poor & Poor & No & Late death \\
2 & $3 y$ & M & DS & Yes & Poor & Poor & No & Cardiac transplantation \\
3 & $7 y$ & M & DS & No & Good & Poor & Yes, AVR & Late death \\
4 & $6 y$ & M & DS & Yes & Good & Moderate & Moderate AR & NYHA II \\
5 & $9 \mathrm{mo}$ & F & DS & Yes & Poor & Poor & No & NYHA III \\
6 & $4.5 y$ & F & DS & Yes & Good & Moderate & No & NYHA II \\
7 & $10 \mathrm{mo}$ & M & DS & No & Good & Moderate & No & NYHA I \\
8 & $14 \mathrm{mo}$ & F & RS & No & Good & Moderate & No & NYHA I \\
9 & $6 y$ & M & RS & No & Good & Moderate & No & NYHA I \\
\hline
\end{tabular}

Of 9 patients, 6 had new postoperative LV impairment, 2 in the presence of aortic regurgitation. DS, Double-switch procedure; AVR, aortic valve replacement; $A R$, aortic regurgitation; $R S$, Rastelli-Senning procedure.

${ }^{*}$ Age at double-switch or Rastelli-Senning operation.

in the Rastelli-Senning group with significant tricuspid regurgitation before the operation had no regurgitation at his most recent echocardiogram. The patient with a dysplastic mitral valve before the operation has undergone mitral valve repair as discussed previously, and the patient with moderate mitral regurgitation and poor $\mathrm{LV}$ function has undergone cardiac transplantation. No patients have acquired either moderate or severe mitral regurgitation since their correction.
PA Banding For LV Training

All 9 patients who underwent PA banding to train the LV are currently alive. Five are in NYHA functional class I, 2 are in NYHA functional class II, 1 is in NYHA functional class III, and 1 has undergone cardiac transplantation. Excluding the transplant patient, 5 have good LV function at follow-up and 2 have moderate LV function, 1 in the presence of moderate aortic regurgitation. In 1 patient with significant $\mathrm{LV}$ dysfunction before the operation, the LV function re- 
mains poor. Of the 9 patients, 3 have acquired aortic regurgitation, and 1 of these has undergone aortic valve replacement.

\section{Discussion}

The surgical approaches for patients with CCTGA fall practically and conceptually into two different groups. Classic repair deals solely with the problems associated with the condition, such as tricuspid regurgitation, a VSD, or LV outflow obstruction. Anatomic repair, however, deals with the root of the defect itself by restoring the LV to the systemic circulation. Intuitively this seems more sensible, and conceptually it is certainly more appealing. Furthermore, one of the most important associations of CCTGA, tricuspid regurgitation, is largely eliminated in most cases after anatomic repair, usually without any specific operation on the valve itself. This is important because of the strong association of tricuspid regurgitation with systemic RV dysfunction and ultimately late death after classic repair. ${ }^{1-3,15}$

The early results after classic repair are on the whole quite good; however, the results in the medium to long term are disappointing and have resulted in a more recent tendency toward anatomic correction. A particular problem with classic repair seems to be a high incidence of late death caused by cardiac failure. In a series of 40 patients undergoing classic repair reported by van Son and colleagues, ${ }^{2}$ the principal cause of death in all early deaths (4 patients) and all late deaths (12 patients) was systemic ventricular failure. In a series of 99 patients reported by McGrath and colleagues, ${ }^{15}$ late death was due to cardiac failure in $70 \%$ of the those who died. This was also true for $55 \%$ of the patients who died late in the series of 52 patients reported by Termignon and coworkers. ${ }^{1}$ The authors in the last-mentioned study concluded that the results of classic repair are unsatisfactory, not only because of the high incidence of heart failure in their series but also because of a $15 \%$ operative mortality, an $80 \%$ incidence in reoperative tricuspid valve replacement or repair in those with a VSD, and a $27 \%$ incidence of atrioventricular block. A more recent series of 118 patients undergoing classic repair at the Hospital for Sick Children (Toronto, Ontario, Canada) suggested that alternative management to classic repair in patients with CCTGA should be examined because of the cumulative increases in mortality (48\% survival at 20 years), tricuspid valve replacement, complete atrioventricular block (33\%), and the incidence of reoperation (56\% required reoperation within 20 years). ${ }^{16}$

The current series of 54 patients undergoing anatomic repair of CCTGA to our knowledge represents the largest reported to date. Direct comparison between series is not easy because of the variations in patient numbers, associated lesions, and time frame of the repair. Furthermore, comparisons between anatomic and classic repair series are likely to be biased in favor of a classic repair because patients with CCTGA and severe RV dysfunction are not suitable candidates for a classic repair. The early mortality of 5.6\% (3 patients) in our series compares favorably with most of the larger series of patients undergoing classic repair, in which operative mortality has varied between $10 \%$ and $16 \%,{ }^{1,2,17,18}$ although the large series by Yeh and associates ${ }^{16}$ had an equivalent mortality of $6 \%$. A similar mortality of $4 \%$ was reported in a smaller series by Sano and colleagues, ${ }^{3}$ but mortality as high as $33 \%$ has also been reported after classic repair. ${ }^{19}$ The two largest published series of anatomic correction to date reported an operative mortality of $9 \%$ in 44 patients ${ }^{9}$ and an impressive zero mortality in 22 patients. ${ }^{8}$ In the other smaller series of patients undergoing anatomic repair, operative mortality has varied between zero and $14 \% .^{10-12,20,21}$

The most frequent early complication after surgical correction of CCTGA is complete heart block. ${ }^{1,15,16}$ Patients with CCTGA are at risk for compete atrioventricular block even without surgery, and it has been estimated to affect approximately $2 \%$ of patients per year after diagnosis. ${ }^{22}$ In our series $7(14 \%)$ of the 51 patients in sinus rhythm before the operation acquired permanent complete heart block after the operation. In the double-switch group the VSD sutures were placed from the RV side of the VSD superiorly to avoid the bundle of His, as described by de Leval and coworkers, ${ }^{23}$ and in the Rastelli-Senning group the VSD was always closed from the RV side. Despite these measures, permanent atrioventricular block occurred. This suggests that development of heart block may be related to factors other than suture placement or enlargement of the VSD, such as retraction of the heart. Most series of patients undergoing classic repair have had an incidence of complete atrioventricular block after surgery of between $20 \%$ and $33 \%,{ }^{1,15,16,18}$ although in one series of 40 patients there were no cases of surgically induced complete heart block. ${ }^{2}$ The incidence of complete atrioventricular block after anatomic repair has been variously reported as zero, ${ }^{11,21} 9 \%,{ }^{8}$ and $30 \%{ }^{12}$ With the exception of one series of patients undergoing anatomic repair ${ }^{12}$ and one series of patients undergoing classic repair, ${ }^{2}$ the incidence of complete heart block after repair tends to be lower after anatomic repair than after classic repair. The other frequent early complication was prolonged chest tube drainage in the RastelliSenning group. This has been noted in the absence of any significant anatomic defects in previous series ${ }^{10}$ and is likely to be related to the RV dysfunction that follows a right ventriculotomy.

Overall long-term survival in our series was $94 \%$ at 1 year, falling to $90 \%$ at 4 years and from there on out to 9 years. Survivals for patients undergoing double-switch procedures were $93 \%$ at 1 year and $85 \%$ at 5 and 7 years, and in the Rastelli-Senning group survival was $96 \%$ at 1 and 7 
years. The number of patients available for follow-up is fairly small; however, these are currently the only published actuarial survival figures for patients undergoing anatomic correction of CCTGA. With regard to patients undergoing a classic repair, there is some consistency between the larger series, with 10 -year survival tending to vary between $60 \%$ and $70 \%{ }^{1,2,15,17,18,24}$ The only previously identified risk factor for decreased long-term survival after classic repair is the presence of preoperative tricuspid regurgitation. ${ }^{24}$ The very best survival figures after classic repair are those reported in a series of 28 patients by Sano and colleagues, ${ }^{3}$ with a 5- and 10 -year survival of $83 \%$. The results of our study suggest that anatomic repair may well result in an improvement in long-term outcome for patients relative to the classic strategy.

Freedoms from reoperation for the entire series were $94 \%$ at 1 year, $85 \%$ at 5 years, and $76 \%$ at 9 years. On analyzing the groups separately, freedoms from reoperation were $93 \%$ and $96 \%$ at 1 year and $87 \%$ and $68 \%$ at 7 years in the double-switch and Rastelli-Senning groups, respectively. Smaller numbers have prevented a similar analysis in other series of anatomic repairs for CCTGA. With increased follow-up the incidence of reoperation in the Rastelli-Senning group will increase, because ultimately these patients are all likely to require a conduit change. Freedom from reoperation in these patients is likely to reflect the longevity of the Hancock conduit. Although this is also true after classic repair, the prevalence of systemic atrioventricular valve failure $^{1}$ is likely to result in a considerably higher incidence of reoperation in the longer term in patients who have undergone a classic approach. In a recent large series from the Mayo Clinic (Rochester, Minn), the cumulative probability of reoperation after classic repair was $41 \%$ by 10 years. ${ }^{17}$ The series from Hospital for Sick Children has a long follow-up, with a 16-year freedom from reoperation of $43 \%$. By the age of 40 years, $47 \%$ of patients had required tricuspid valve surgery, and within 20 years, $56 \%$ had required reoperation, usually for atrioventricular valve incompetence or pulmonary stenosis. ${ }^{16}$

In the Rastelli-Senning group we favored the use of a Hancock valved conduit because it provides the long length necessary to connect the PAs to the RV and allows the valve to be positioned distally without the use of a separate additional tube conduit proximally. The conduit usually lies behind the sternum, and placement of a polytetrafluoroethylene membrane between the conduit and the sternum has facilitated conduit change. Removal of the Hancock valved conduit from its fibrous sheath has been relatively easier to achieve than dissection out of a calcified homograft conduit. Conduit change has so far been undertaken in 3 patients without difficulty.

Certain features are becoming clearer in the follow-up of our patients, particularly in relation to the improvement in tricuspid regurgitation that we have observed. Some reduction in tricuspid regurgitation was observed in 3 of the 6 patients who had PA bands placed to train the LV for longer than 6 months. This observation has been made previous$1 y,{ }^{19}$ and the assumption is that the increase in LV pressure caused by banding alters septal geometry, pushing the septal leaflet of the tricuspid valve into the RV. This is probably particularly important if the septal leaflet is attached to the septum, as in Ebstein-like valves. The improvement in tricuspid regurgitation after banding was not a consistent finding in our series, however, with 3 patients still having severe tricuspid regurgitation at the time of their repair and 2 having moderate tricuspid regurgitation. After the doubleswitch procedure, however, there was a marked reduction in tricuspid regurgitation in all patients, even in the presence of severe dysplasia of the tricuspid valve. In our series 18 patients had moderate to severe tricuspid regurgitation before the operation, with 2 of these undergoing tricuspid valve repair at the time of the double-switch procedure. At latest follow-up only 2 patients have moderate tricuspid valve regurgitation on echocardiography, and in both cases it is clinically insignificant. Similar observations have been made in previous studies. ${ }^{8,9,20}$ In addition, no patients have had development of either moderate or severe mitral regurgitation since their repair.

In contrast, a secondary increase in tricuspid regurgitation or emergence of new tricuspid regurgitation is a significant problem after classic repair. ${ }^{1,19}$ In a recent series from the Mayo Clinic, 14 patients had either no or trivial tricuspid regurgitation before the operation; however, only 2 were free of important tricuspid regurgitation at followup. ${ }^{17}$ Acar and coworkers ${ }^{19}$ commented that repair of the tricuspid valve always failed when the RV was left in a systemic position and always succeeded when the RV was placed in a subpulmonary position. Restoration of the RV to the subpulmonary position is certainly a more efficient way of achieving tricuspid valve competence than any direct attempt to repair the tricuspid valve. Tricuspid valve function in CCTGA seems to depend on the loading conditions of the ventricles and on the septal geometry. Strategies that result in an increase in RV volume or a decrease in LV pressure are likely to induce tricuspid regurgitation. In contrast, when RV volume decreases or LV pressure increases, tricuspid valve function improves.

A total of 9 patients had evidence of LV impairment after the operation. Three patients were known to have poor ventricular function before the operation; 1 of them had undergone PA banding to train the LV and acquired suprasystemic LV pressure with an LV that was failing before the double-switch procedure. In this case the band may have been too tight or have been left on for too long. Of the 6 patients with new LV impairment after the operation, 2 had aortic regurgitation and subsequently acquired LV dysfunc- 
tion in association with this. Four patients ( 2 in the doubleswitch group and 2 in the Rastelli-Senning group) thus had new postoperative impaired LV function without any associated aortic regurgitation. Three of these 4 are currently free of symptoms and in NYHA class I; whether progressive and clinically important LV dysfunction develops in the future remains to be seen. In general, LV dysfunction has not been a feature of patients undergoing anatomic repair, ${ }^{10,11,20,21}$ although there are occasional reports of deterioration in LV function after the operation. ${ }^{13}$ In the series of 22 patients reported by Inamura and colleagues, ${ }^{8} 1$ patient acquired moderate LV dysfunction at 5 months after the operation, and 2 acquired mild LV impairment in the series of 14 double-switch procedures reported by Karl and associates. ${ }^{12}$ Careful follow-up of the group as a whole will help us to determine the long-term significance of this problem.

Aortic regurgitation was present to some degree in most of our patients after the double-switch procedure. It was usually mild; however, 4 patients acquired either moderate or severe aortic regurgitation, and 2 of these have undergone aortic valve replacement. In this situation it is important to intervene and replace the valve before the LV dilates. That the presence of a PA band may well result in subsequent distortion of the neoaortic valve is suggested by the fact that 3 of the 4 patients who acquired significant aortic regurgitation had undergone previous PA banding. Aortic valve regurgitation has not been a feature of the Rastelli-Senning and Senning-tunnel procedures. Neither has it been a feature of most series of anatomic repairs. Acute early postoperative aortic regurgitation has been reported previously in one other series though, ${ }^{9}$ and mild neoaortic regurgitation was present in 2 of 12 surviving patients in the series of Karl and associates. $^{12}$

During the past 10 years, as our experience with anatomic correction of CCTGA has increased, our strategy for managing this group of patients has become more clearly defined. Broadly speaking, we have four different management strategies that depend on the patient's clinical situation.

First, patients with CCTGA and a VSD usually need PA banding early in life and tend to stabilize for a few years after this. Septation is needed before the child outgrows the band, and currently we believe that anatomic correction is the best option for these patients. Although there may be problems with the morphologically LV as the systemic ventricle in the future, we are unlikely to have a clear answer to this for many years.

Second, patients with tricuspid regurgitation, an intact septum with congestive cardiac failure, and at least a moderate degree of RV dysfunction have limited options. In this group the RV is failing as the systemic ventricle, and rendering the tricuspid valve competent in this setting is likely to make the RV dysfunction worse. The only surgical options for these patients are a double-switch procedure or cardiac transplantation. Some of these patients are in extremis with significant inotrope requirement and ventilator dependence, and in these cases it is a lifesaving procedure.

Third, for patients with CCTGA and tricuspid regurgitation who begin to have RV dysfunction, we consider PA banding to train the LV followed by a double-switch to be the right approach at present. Patients who have previously undergone a classic repair and acquire secondary RV failure with or without tricuspid regurgitation after surgery should also be included in this group and should undergo a doubleswitch procedure, providing the LV can be trained by PA banding.

Finally, patients with CCTGA and pulmonary stenosis or atresia and significant associated cyanosis usually require systemic-PA shunting early in life. A Rastelli-Senning type of repair is undertaken, providing the VSD can be tunneled to the aorta. This can usually be delayed a few years, allowing a larger conduit to be used at the time of repair.

Certain groups of patients with CCTGA may not be suitable for anatomic repair, including older patients who may not respond to PA banding and younger patients with anatomic or morphologic contraindications. The presence of a straddling atrioventricular valve or an inlet VSD with no outlet extension, for example, would make it difficult to tunnel the VSD to the aorta without compromising the volume of the RV because of the size of the baffle. We suggest that patients who have well-balanced systemic and pulmonary circulations without marked desaturation ,usually in association with a VSD and moderate pulmonary stenosis, are best managed conservatively without surgical intervention until such time as they show symptoms.

In conclusion, anatomic repair of CCTGA can be carried out with a relatively low early mortality. At present it seems that when operative intervention is indicated, anatomic correction is the procedure of choice. Excellent functional status can be achieved, with good midterm survival. Continued surveillance is necessary for patients with valved conduits and also to determine the longer-term function of both the aortic valve and the morphologically LV in the systemic circulation.

\section{References}

1. Termignon JL, Leca F, Vouhé PR, Vernant F, Bical OM, Lecompte Y, et al. "Classic" repair of congenitally corrected transposition and ventricular septal defect. Ann Thorac Surg. 1996;62:199-206.

2. van Son JA, Danielson GK, Huhta JC, Warnes CA, Edwards WD, Schaff HV, et al. Late results of systemic atrioventricular valve replacement in corrected transposition. J Thorac Cardiovasc Surg. 1995; 109:642-53.

3. Sano T, Riesenfeld T, Karl TR, Wilkinson JL. Intermediate-term outcome after intracardiac repair of associated cardiac defects in patients with atrioventricular and ventriculoarterial discordance. Circulation. 1995;92(9 Suppl):II272-8.

4. Siebenmann R, von Segesser L, Schneider K, Schneider J, Senning A, 
Turina M. Late failure of systemic ventricle after atrial correction for transposition of great arteries. Eur J Cardiothorac Surg. 1989;3:11924.

5. Di Donato RM, Troconis CJ, Marino B, Carotti A, Iorio FS, Rossi E, et al. Combined Mustard and Rastelli operations. An alternative approach for repair of associated anomalies in congenitally corrected transposition in situs inversus [I,D,D]. J Thorac Cardiovasc Surg. 1992;104:1246-8.

6. Ilbawi MN, DeLeon SY, Backer CL, Duffy CE, Muster AJ, Zales VR, et al. An alternative approach to the surgical management of physiologically corrected transposition with ventricular septal defect and pulmonary stenosis or atresia. J Thorac Cardiovasc Surg. 1990;100: 410-5.

7. Yamagishi M, Imai Y, Hoshino S, Ishihara K, Koh Y, Nagatsu M, et al. Anatomic correction of atrioventricular discordance. $J$ Thorac Cardiovasc Surg. 1993;105:1067-76.

8. Imamura M, Drummond-Webb JJ, Murphy DJ Jr, Prieto LR, Latson LA, Flamm SD, et al. Results of the double switch operation in the current era. Ann Thorac Surg. 2000;70:100-5.

9. Imai Y. Double-switch operation for congenitally corrected transposition. Adv Cardiac Surg. 1997;9:65-86.

10. Sharma R, Bhan A, Juneja R, Kothari SS, Saxena A, Venugopal P. Double switch for congenitally corrected transposition of the great arteries. Eur J Cardiothorac Surg. 1999;15:276-81.

11. Reddy VM, McElhinney DB, Silverman NH, Hanley FL. The double switch procedure for anatomical repair of congenitally corrected transposition of the great arteries in infants and children. Eur Heart $J$. 1997; 18:1470-7.

12. Karl TR, Weintraub RG, Brizard CP, Cochrane AD, Mee RB. Senning plus arterial switch operation for discordant (congenitally corrected) transposition. Ann Thorac Surg. 1997;64:495-502.

13. Yagihara T, Kishimoto H, Isobe F, Yamamoto F, Nishigaki K, Matsuki $\mathrm{O}$, et al. Double switch operation in cardiac anomalies with atrioventricular and ventriculoarterial discordance. $J$ Thorac Cardiovasc Surg. 1994;107:351-8.

14. Stumper O, Wright JG, De Giovanni JV, Silove ED, Sethia B, Brawn WJ. Combined atrial and arterial switch procedure for congenital corrected transposition with ventricular septal defect. Br Heart J. 1995;73:479-82

15. McGrath LB, Kirklin JW, Blackstone EH, Pacifico AD, Kirklin JK, Bargeron LM Jr. Death and other events after cardiac repair in discordant atrioventricular connection. J Thorac Cardiovasc Surg. 1985; 90:711-28.

16. Yeh T Jr, Connelly MS, Coles JG, Webb GD, McLaughlin PR, Freedom RM, et al. Atrioventricular discordance: results of repair in 127 patients. J Thorac Cardiovasc Surg. 1999;117:1190-203.

17. Biliciler-Denktas G, Feldt RH, Connolly HM, Weaver AL, Puga FJ, Danielson GK. Early and late results of operations for defects associated with corrected transposition and other anomalies with atrioventricular discordance in a pediatric population. $J$ Thorac Cardiovasc Surg. 2001;122:234-41.

18. Szufladowicz M, Horvath P, de Leval M, Elliott M, Wyse R, Stark J. Intracardiac repair of lesions associated with atrioventricular discordance. Eur J Cardiothorac Surg. 1996;10:443-8.

19. Acar P, Sidi D, Bonnet D, Aggoun Y, Bonhoeffer P, Kachaner J. Maintaining tricuspid valve competence in double discordance: a challenge for the paediatric cardiologist. Heart. 1998;80:479-83.

20. Imai Y, Sawatari K, Hoshino S, Ishihara K, Nakazawa M, Momma K. Ventricular function after anatomic repair in patients with atrioventricular discordance. J Thorac Cardiovasc Surg. 1994;107:1272-83.

21. Metras D, Kreitmann B, Fraisse A, Riberi A, Wernert F, Nassi C, et al Anatomic repair of corrected transposition or atrio-ventricular discordance: report of 8 cases. Eur J Cardiothorac Surg. 1998;13:117-23.

22. Huhta JC, Maloney JD, Ritter DG, Ilstrup DM, Feldt RH. Complete atrioventricular block in patients with atrioventricular discordance. Circulation. 1983;67:1374-7.

23. de Leval MR, Bastos P, Stark J, Taylor JF, Macartney FJ, Anderson RH. Surgical technique to reduce the risks of heart block following closure of ventricular septal defect in atrioventricular discordance. J Thorac Cardiovasc Surg. 1979;78:515-26.
24. Huhta JC, Danielson GK, Ritter DG, Ilstrup DM. Survival in atrioventricular discordance. Pediatr Cardiol. 1985;6:57-60.

\section{Discussion}

Dr Pedro J. del Nido (Boston, Mass). To my knowledge, this article represents one of the largest series presented from any single institution. What I'd like to do, because this is a varied group of patients, is divide it up into the different subgroups for my comments and questions.

First of all, Dr Langley, regarding the group that did not have significant pulmonary or subpulmonary obstruction, the group that underwent double-switch procedures, I noticed that in a large percentage of those patients PA banding was used either as a method of controlling pulmonary overcirculation, which you did in 13 of your patients, or as a method for preparation of the LV. Subsequently, several patients either have required reintervention or have some degree at least of neoaortic valve regurgitation. Can you speculate on the role that banding may have either in the generation of aortic regurgitation early on or in the degree of ventricular dysfunction that was seen in a small percentage?

Also in that group, in light of your current experience with arterial switch and neonatal surgery, if you had a child younger than 1 year without subpulmonary obstruction who was in congestive heart failure, would you undertake banding now in an effort to obtain time, or would you simply go directly to a repair?

Dr Langley. The question regarding the influence of PA banding on neoaortic regurgitation is quite difficult to answer. Of the 4 patients who subsequently acquired aortic regurgitation, 3 had undergone previous PA banding. It is certainly conceivable that the presence of a PA band could result in subsequent distortion of the neoaortic valve and it may be that this is the price we have to pay for this kind of approach.

With regard to the hypothetical infant with congestive heart failure, would we place a PA band? I think it would depend on the severity of the child's symptoms. One of the things that has become more clearly defined during the 10 years of undertaking these procedures is indication for operation. In the context of a child with an intact ventricular septum who has tricuspid regurgitation and deteriorating RV function, if we were able to band the child to train the RV, then we would. But a number of patients, including 5 in this series, have severe tricuspid regurgitation and severe RV dysfunction. These 5 patients were receiving ventilatory and inotropic support before the operation, and in that situation you really may not have time to band. Your options are limited to either cardiac transplantation or proceeding straightaway to a double-switch procedure without banding.

Dr del Nido. I think one of the questions would be timing. It is clear that children with pulmonary overcirculation are at greater risk for premature development of tricuspid regurgitation, and perhaps avoiding banding by early intervention might be worthwhile.

The second two groups are subgroups of the Rastelli-Senning group. Clearly, conduit position is an important issue, especially in the group with dextrocardia, simply because the position of the conduit is usually retrosternal and compression of the conduit is a not infrequent problem. I noticed that, you chose to use a Hancock conduit, which is a reinforced conduit, and I would like you to comment on why you chose that conduit. Also, I noted that in 